\title{
Impact of EGFR immunoexpression on STAT3 activation and association with proinflammatory/regulatory cytokine pattern in laryngeal squamous cell carcinoma
}

\author{
KATARZYNA STARSKA ${ }^{1}$, MAGDALENA BRYS ${ }^{2}$, EWA FORMA ${ }^{2}$, \\ EWA GLOWACKA ${ }^{3}$, IWONA LEWY-TRENDA ${ }^{4}$, OLGA STASIKOWSKA ${ }^{4}$, \\ WANDA M. KRAJEWSKA ${ }^{2}$ and MAREK LUKOMSKI ${ }^{1}$
}

\begin{abstract}
${ }^{1}$ Department of Otolaryngology and Laryngological Oncology, Medical University of Lodz, Kopcinskiego 22, 90-153 Lodz; ${ }^{2}$ Department of Cytobiochemistry, University of Lodz, Banacha 12/16, 90-237 Lodz; ${ }^{3}$ Department of Immunology, Polish Mother's Health Memorial Hospital, Research Institute, Rzgowska 281, 93-338 Lodz;

${ }^{4}$ Department of Pathology, Medical University of Lodz, Pomorska 251, 92-213 Lodz, Poland
\end{abstract}

Received August 18, 2008; Accepted October 6, 2008

DOI: 10.3892/or_00000255

\begin{abstract}
Stimulation of epidermal growth factor receptor (EGFR) results in the activation of signal transducer and activator of transcription-3 (STAT3), a transcriptional factor associated with carcinogenesis. Proinflammatory cytokines are capable of activating a tumor cell death program by reducing EGFR tyrosine phosphorylation. This study aimed to identify EGFR expression in laryngeal carcinoma and determine the relationship with STAT3 and proinflammatory/ regulatory cytokine secretion. An analysis of EGFR expression (membranous EGFR-m and cytoplasmic EGFR-c) was performed in tumor tissues by immunohistochemical (IHC) staining in 45 medical cases of laryngeal carcinoma. STAT3 expression in freshly isolated tumor and non-cancerous normal epithelial cells by RT-PCR was analyzed in 24 patients after total larynx resection. The concentrations of TNF $\alpha$, IL-2, IL-6, IL-8 and IFN $\gamma$ secreted by purified peripheral blood mononuclear cells (PBMCs) or contained in whole blood samples were measured by ELISA. The relationship between EGFR and mRNA STAT3 expression as well as the level of secreted cytokines was investigated. In our study, 93.3\% tumors expressed EGFR-m and 37.8\% EGFR-c. It also revealed a statistically significant dependence of the EGFR status on STAT3 expression in neoplastic tissues. Tumors with IHC EGFR-m positive staining $>50 \%$ of the total number of cells, as well as with EGFR-c positive staining,
\end{abstract}

Correspondence to: Dr Katarzyna Starska, Department of Otolaryngology and Laryngological Oncology, Medical University of Lodz, Kopcinskiego 22, 90-153 Lodz, Poland

E-mail: katarzyna.starska@op.pl

Key words: laryngeal carcinoma, epidermal growth factor receptor, proinflammatory/regulatory cytokines, signal transducer and activator of transcription-3 factor were characterized by the most frequent presence of STAT3 expression. Our data demonstrate a significant negative relationship between EGFR-m expression and TNF $\alpha$ concentration, and a positive connection between membranous EGFR and IL-8 or IFN $\gamma$ levels recorded in isolated PBMCs. Furthermore, this study revealed a significant relationship between EGFR-c immunoexpression and IL- 8 or IFN $\gamma$ concentration. Our findings have confirmed a key role of EGFR in determining the proliferative and malignant potential of laryngeal carcinoma.

\section{Introduction}

Epidermal growth factor receptor (EGFR, ErbB1 and HER1) is a member of the ErbB receptor family and a type I tyrosine kinase receptor. It occurs as a transmembrane glycoprotein, which undergoes autophosphorylation and triggers signaling pathways involving the signal transducer and activator of transcription-3 (STAT3), phosphatydylinositol 3'-kinase/ protein kinase $\mathrm{B}\left(\mathrm{PI}_{3} \mathrm{~K} / \mathrm{Act}\right)$, mitogen-activated protein kinase (MAPK), nuclear factor-kB (NF-kB), c-Myc, cyclin D1 and extracellular signal-related protein kinase 1/2 (Erk1/2) pathways (1-7). It is known as a key regulator of cellular proliferation and cell survival by cell cycle progression, inhibition of cell death, regulation of cell migration, tumor invasion and differentiation in a wide variety of human carcinoma types, such as head and neck carcinoma, cancer of the breast, colon, bladder, lung, kidney, esophagus, stomach and pancreas cancer (8-10).

A large number of malignancies of epithelial origin have been characterized by the overexpression of EGFR and/or its ligands, such as epidermal growth factor (EGF), transforming growth factor- $\alpha(\mathrm{TGF} \alpha)$ and amphiregulin $(11,12)$. The amplification of genes encoding EGFR has also been noted in previous studies (13-15). The involvement of STAT3, as a latent transcriptional factor, in the activation of apoptosis and cell cycle progression, and its impact on carcinogenesis in various neoplasms were demonstrated $(6,7,16-18)$. EGFR 
stimulation, as with other mechanisms connected with IL-6R, VEGF and HGF signaling, results in the EGFR-dependent activation of the STAT3 controlling gene expression (19-22). A positive correlation between elevated EGFR activity, including kinase domain-activating mutant EGFR and STAT3 has been described for many human primary tumors $(19,23$ 26). In squamous cell head and neck carcinomas (HNSCC), constitutively active STAT3 has been shown to be associated with EGFR signaling and deregulated cell growth $(20,21,27$, 28). Nevertheless, several studies have been reported, which demonstrate the interaction of proinflammatory cytokines with EGFR as well as the effects of antitumor cytokine connected with the activation of cell death program (29-33).

It is known that $\mathrm{TNF} \alpha$ is capable of activating tumor cell apoptosis through receptor clustering and the stimulation of caspases (caspase-8) $(31,32)$. Evidence for the stimulation of protein tyrosine phosphatase and the reduction of EGFR tyrosine phosphorylation by TNF $\alpha$ has been provided. Thus, decreased EGFR tyrosine phosphorylation leads to the blockade of the EGFR-mediated signal transduction (32). Another mechanism resulting in an increased EGFR expression and connected with the stimulation of TNF $\alpha$ receptor has also been noted (32,34-36). Evidence suggested that the overexpression of tyrosine kinase activity EGFR may suppress the antiproliferative or cytotoxic activity of TNFa $(32,36)$. Interestingly, EGFR expression can be increased by TNFa via the p55 receptor (36). This effect of TNFa on EGF receptor tyrosine phosphorylation in tumor cells depended on the sensitivity or resistance to TNF $\alpha$ of cell variants selected for apoptotic and tyrosine kinase signaling processes (32). However, few studies introducing a new target of overexpressed EGFR by using the combination of monoclonal antibodies and TNF $\alpha$ to abrogate the host immune response resulting in enhanced tumor regression, have been presented in the literature $(31,32)$.

Previous data suggested a new method of targeting EGFR signaling in epithelial tissue tumors. It has been demonstrated that the EGFR pathway was inhibited by blocking the activity of a key protease $\mathrm{TNF} \alpha$-converting enzyme (TACE, disintegrin and metalloproteinase 17$)$, which regulates the bioavailability of EGFR ligands (3,37-39). Persistently activated mutant EGFR has been shown to be connected with the production of high IL- 6 levels, leading to the increase in carcinogenesis via the IL-6/gp130/JAK pathway $(19,20)$. The epigenetic regulation of gene expression resulting in IL-6 overexpression can escalate tumor progression by altering promoter methylation and gene expression of growth regulators such as EGFR (40). EGFR, TGF $\alpha$ and MAP kinase ERK1/2 are also involved in the mechanism of IL-8 production $(3,41,42)$. Moreover, signaling through EGFR can lead to the $\mathrm{PI}_{3} \mathrm{~K} /$ Act pathway and may increase hypoxiainducible factor (HIF) activity which is responsible for stimulating cytokines and growth factors (2).

Our study aimed to analyze cytoplasmic and membranous EGFR expression in squamous cell laryngeal carcinoma, investigate the relationship between EGFR status and STAT3 expression in tumor cells, evaluate the secretion level of proinflammatory/regulatory cytokines (TNF $\alpha$, IL-2, IL-6, IL- 8 and IFN $\gamma$ ) and become familiar with their role in determining the proliferative and aggressive tumor potential.
Table I. Clinical characteristics of patients.

\begin{tabular}{|c|c|c|}
\hline Feature & No. of patients & $\%$ \\
\hline Total no. & 45 & \\
\hline \multicolumn{3}{|l|}{ Gender } \\
\hline Men & 43 & 95.6 \\
\hline Women & 2 & 4.4 \\
\hline \multicolumn{3}{|l|}{ Surgical treatment } \\
\hline Complete laryngectomy & 24 & 53.3 \\
\hline Partial laryngectomy & 21 & 46.7 \\
\hline Lymphadectomy (+) & 19 & 42.2 \\
\hline Lymphadectomy (-) & 26 & 57.6 \\
\hline \multicolumn{3}{|l|}{$\mathrm{pT}$} \\
\hline pT2 & 14 & 31.1 \\
\hline pT3 & 17 & 37.8 \\
\hline pT4 & 14 & 31.1 \\
\hline \multicolumn{3}{|l|}{$\mathrm{pN}$} \\
\hline pNO & 31 & 68.9 \\
\hline $\mathrm{pN} 1-3$ & 14 & 31.1 \\
\hline \multicolumn{3}{|l|}{ EGFR-m (\%) } \\
\hline$<25$ & 17 & 37.8 \\
\hline $25 \div 50$ & 9 & 20.0 \\
\hline$>50$ & 19 & 42.2 \\
\hline \multicolumn{3}{|l|}{ EGFR-c } \\
\hline None & 28 & 62.2 \\
\hline Weak to moderate & 11 & 24.5 \\
\hline Strong & 6 & 13.3 \\
\hline
\end{tabular}

\section{Materials and methods}

Tissue samples, histological classification and morphological features. For this study, 45 cases (43 men and 2 women, aged $48-83$ years, mean age $58 \pm 5$ years) of archival tissue samples and paraffin-embedded tissues of surgically resected specimens from patients treated for squamous cell laryngeal carcinoma were utilized. Each patient underwent complete $(53,3 \% ; 24 / 45)$ or partial $(46,7 \% ; 21 / 45)$ surgical resection of the larynx and $42.2 \%(19 / 45)$ of the patients underwent dissection of the cervical lymph nodes with pathological confirmation of the metastases (pN1-3) in $31.1 \%$ $(14 / 45)$ of cases. The lesions were assessed according to the criteria of the International Union Against Cancer (UICCTNM 2002) (43). Criteria for patient participation in this study were: i) a histologically confirmed diagnosis of carcinoma planoepitheliale, ii) primary surgical resection without receiving prior immuno-, radio- or chemotherapy and iii) absence of distant metastases. Clinical characteristics of patients are shown in Table I.

Immunohistochemistry. Paraffin sections were mounted onto SuperFrost slides, deparaffinized, treated in a microwave 
oven in a solution of citrate buffer, $\mathrm{pH} 6.0$ for $30 \mathrm{~min}(2 \times 5 \mathrm{~min}$ $360 \mathrm{~W}$ and $4 \times 5 \mathrm{~min} 180 \mathrm{~W}$ ) and transferred to distilled water. Endogenous peroxidase activity was blocked by $0.3 \%$ hydrogen peroxide in distilled water for $30 \mathrm{~min}$, and sections were rinsed with Tris-buffered saline (TBS, DakoCytomation, Denmark) and incubated with monoclonal mouse anti-human GEFR antibody (Novocastra Laboratories Ltd. UK, clone: GGFR.113), dilution: 1:75. EnVision+Systems-HRP for mouse and rabbit (DakoCytomation) prepared according to the manufacturer's instructions were used. Visualisation was performed by incubating the sections in a solution of 3,3'diaminobenzidine (DakoCytomation). After washing, the sections were counterstained with hematoxylin and coverslipped. For each antibody and sample a negative control was processed. Negative controls were carried out by incubation in the absence of the primary antibody and always yielded negative results. Within tumor cells, the EGFR protein was detected primarily in the cytoplasm and immunoreactive EGFR protein was detected primarily on the cell membrane. The intensity of immunohistochemical staining as a percentage of tumor cells with EGFR membranous (EGFR-m) expression was scored using a three-tier system: $1,<25 \% ; 2$, $25 \div 50 \%$ and $3,>50 \%$ positive cells. The cytoplasmic staining (EGFR-c) intensity was classified as 0 , none; 1 , weak to moderate and 2, strong. At least 10 high-power fields (magnification, $\mathrm{x} 40$ ) were assessed for each specimen. The slides were assessed in three independent sessions by two investigators.

Lymphocyte isolation and ELISA for TNFa, IL-2, IL-6, IL-8 and IFN $\gamma$ measurement. For PBMC isolation the venous blood of each patient was obtained $(10 \mathrm{ml})$ and transferred to test tubes containing heparin $(10 \mathrm{U} / \mathrm{ml})$. PBMCs were isolated by Ficoll-Hypaque (1077 density) and resuspended at a concentration of $1 \times 10^{6}$ cells $/ \mathrm{ml}$ in RPMI-1640 medium. An experiment in which samples were stimulated with $5 \mu \mathrm{g} / \mathrm{ml}$ of PHA was also performed. The recovered cells were checked and counted for viability with the trypan blue staining method. The isolated PBMC cultures and whole peripheral blood were incubated in 96-well plates at a final volume of $0.2 \mathrm{ml}$ (per well). Culture supernatants were collected after 21 , 42 and $72 \mathrm{~h}$ in $37^{\circ} \mathrm{C}, 5 \% \mathrm{CO}_{2}$ (Cellstar Incubator) and the secretion pattern of cytokines TNF $\alpha$, IL-2, IL-6, IL-8 and IFN $\gamma$ were measured with specific enzyme-linked immunosorbent assays and an ELISA kit (EIA, Pharmingen, USA) according to the manufacturer's protocols. Absorbance was measured with an ELISA reader (Elx808, Bio-Tek Instruments, USA). Each sample was tested in at least three independent ELISA experiments and the data were calculated from three tests for each sample.

Non-cancerous/cancerous epithelium cell isolation. After radical laryngectomy, the surgical tissue specimens were excised aseptically immediately after the operation from at least four tumor sites: two central, two marginal and two sites of normal non-cancerous laryngeal epithelium of the same tumor patients. Tissue fragments were washed with PBS to remove contaminated blood and inserted in RPMI-1640 (Biomed, Lublin, Poland) supplemented with antibiotics streptomycin/penicillin/gentamycin 1\% v/v (Sigma-Aldrich,
Germany). The whole procedure was performed on an ice plateau.

Briefly, tissue specimens were cut with a surgical knife and minced with a scalpel. This was performed in RPMI1640 (Biomed) supplemented with antibiotics streptomycin/ penicillin/gentamycin 2\% v/v (Sigma-Aldrich). Tissue fragments were washed 3 times with Hanks solution (Biomed). The tumor and normal epithelial samples were then digested overnight (for $18 \mathrm{~h}$ ) in Nunc petri-dishes with $0.16 \mathrm{mg} / \mathrm{ml}$ hyaluronidase (Sigma-Aldrich), $0.55 \mathrm{mg} / \mathrm{ml}$ collagenase (Sigma-Aldrich) and antibiotics streptomycin/penicillin/ gentamycin $1 \% \mathrm{v} / \mathrm{v}$ (Sigma, Aldrich) in $37^{\circ} \mathrm{C}, 5 \% \mathrm{CO}_{2}$ (Cellstar Incubator).

The digested tissues were pressed gently through a 50- $\mu \mathrm{m}$ (mesh) sieve (Sigma-Aldrich) with RPMI-1640 (Biomed). Subsequently, the suspension was washed 3 times with PBS (without $\mathrm{Mg}^{2+}$ and $\mathrm{Ca}^{2+}$ ) for 20 min in $8^{\circ} \mathrm{C}$ by centrifugation in an MPW-350R centrifuge at $1800 \mathrm{rpm} / 500 \mathrm{rcf}$, poured over by a dyspase solution of $2.4 \mathrm{U} / \mathrm{ml}$, incubated for $30 \mathrm{~min}$ in $37^{\circ} \mathrm{C}$ and resuspended in $1 \mathrm{ml} \mathrm{PBS}$. Cell concentration was estimated using a microscope and Bürker's chamber. To discard the apoptotic and necrotic cells the columns of magnetic cell sorting separator MACS (Miltenyi Biotec, Germany) and dead cell removal kit were used. Cells were resuspended at a concentration of $1 \times 10^{5}$ cells $/ \mathrm{ml}$ in RPMI1640. The isolated laryngeal cancer (tumor marginal cells, TMC and tumor central cells, TCC) and non-cancerous cells (normal epithelial cells, NCC) were collected immediately after the procedure and frozen at $-70^{\circ} \mathrm{C}$.

RNA extraction and reverse transcription PCR (RT-PCR) analysis. Total RNA was isolated using TRI reagent (SigmaAldrich Co., USA) and quantified by spectrophotometry at $260 \mathrm{~nm}$. RNA with a 260/280 $\mathrm{nm}$ ratio in the range 1.8-2.0 was considered high quality. First-strand cDNA was synthesized from each RNA pool using RNA PCR Kit ver. 3.0 (Takara Shuzo Co., Ltd., Japan) according to the manufacturer's instructions. Briefly, $1 \mu \mathrm{g}$ RNA was combined with 2.5 pmol of oligo dT-adaptor primer, $4 \mu \mathrm{l}$ of $25 \mathrm{mM} \mathrm{MgCl}_{2}, 10 X$ RNA PCR buffer, $2 \mu 1$ of $10 \mathrm{mM}$ dNTP mixture, 20 units of RNase inhibitor, 5 units of AMV reverse transcriptase XL and RNasefree water to a total volume of $20 \mu 1$. The STAT-3 and $\beta$-actin genes, as a standard, were amplified using the specific primers: STAT3(f) 5'-TTG-CCA-GTT-GTG-GTG-ATC-3' and (r) 5'-AGA-ACC-CAG-AAG-GAG-AAG-3' [RefSeq: NM 003150] and B-actin (f) 5'-CGT-GAC-ATT-AAG-GAGAAG-CTG-TGC-3' and (f) 5'-CTC-AGG-AGG-AGC-AATGAT-CTT-GAT-3' [RefSeq: NM 001101]. The thermal cycling parameters were 30 rounds of $1 \mathrm{~min}$ at $94^{\circ} \mathrm{C}, 1 \mathrm{~min}$ at $51^{\circ} \mathrm{C}$ (STAT-3, B-actin) and $3 \mathrm{~min}$ at $72^{\circ} \mathrm{C}$ using a GeneAmp PCR system 9700 (Perkin-Elmer Co., Shelton, USA). The size of the amplified fragments was 313 and 374 bp for STAT-3 and B-actin, respectively.

After amplification, $10 \mu \mathrm{l}$ of PCR products were combined with $1 \mu 1$ of gel-loading buffer and the mixture was electrophoresed on $8 \%$ polyacrylamide gel (acrylamide/bisacrylamide (30/2), 10\% ammonium peroxydisulfate and $0.075 \%$ tetramethyl ethyl-enediamine, at $80 \mathrm{~V}$ for $3 \mathrm{~h}$ in Tris-borate, EDTA, pH 8.0 (TBE) buffer. The gel was silver-stained. To exclude genomic DNA contamination as a source for amplified 


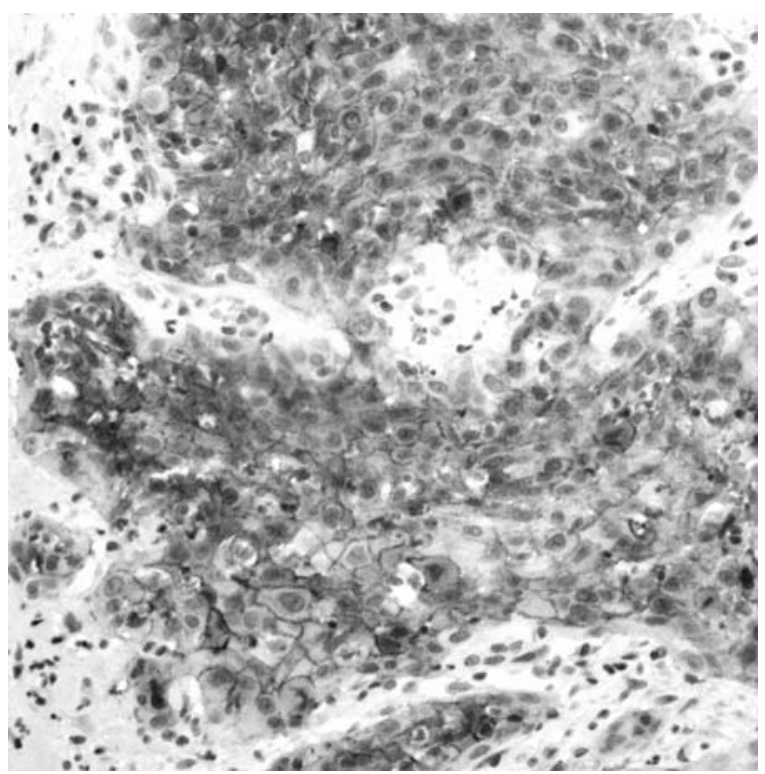

Figure 1. Representative immunohistochemical staining (IHC) for EGFR-m in tumor tissues with an index of $<25 \%$. Original magnification, $x 200$.

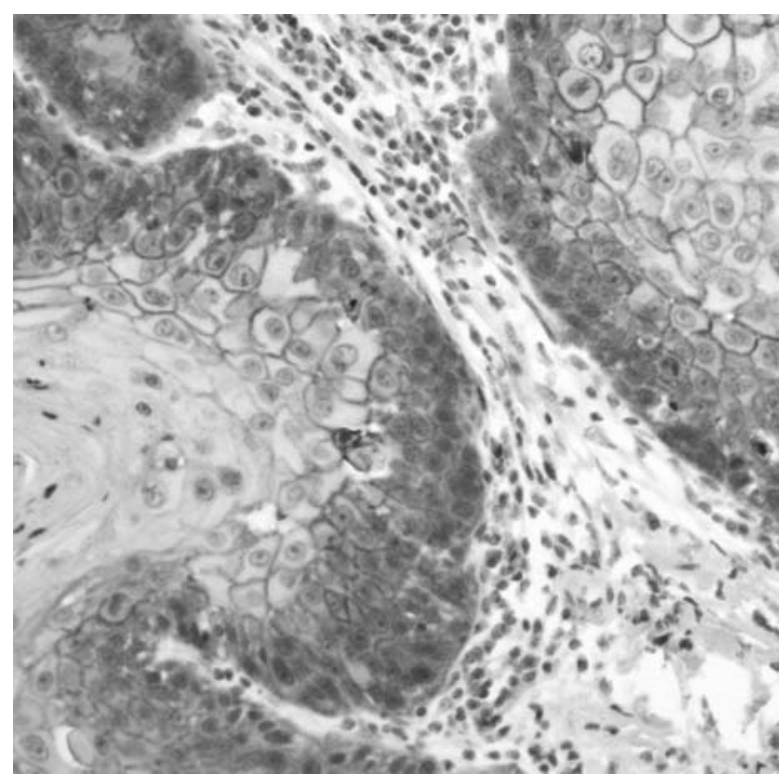

Figure 2. Representative immunohistochemical staining (IHC) for EGFR-m in tumor tissues with an index of $25 \div 50 \%$. Original magnification, $\mathrm{x} 300$.

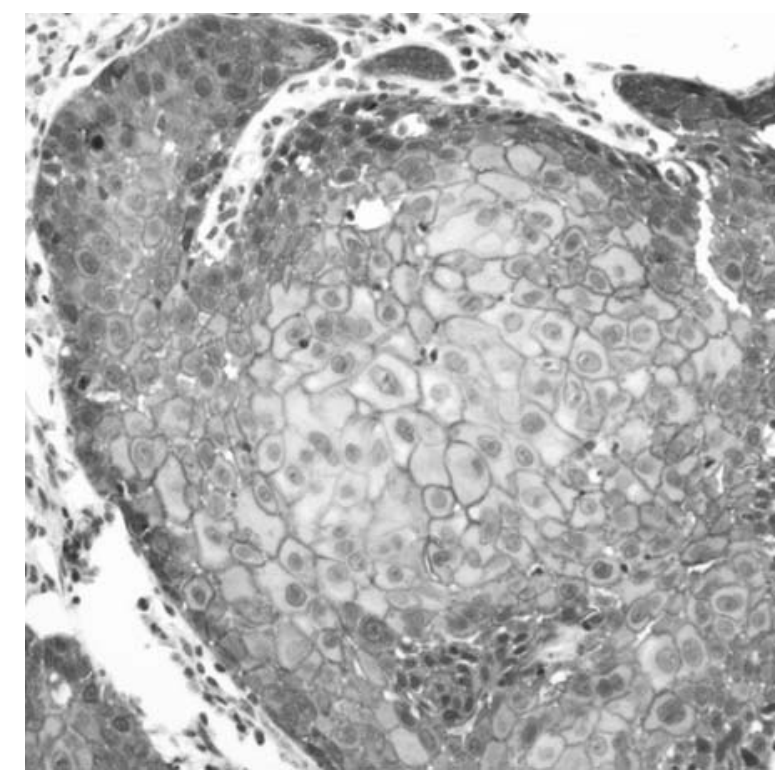

Figure 3. Representative immunohistochemical staining (IHC) for EGFR-m in tumor tissues with an index of $>50 \%$. Original magnification, $x 300$.

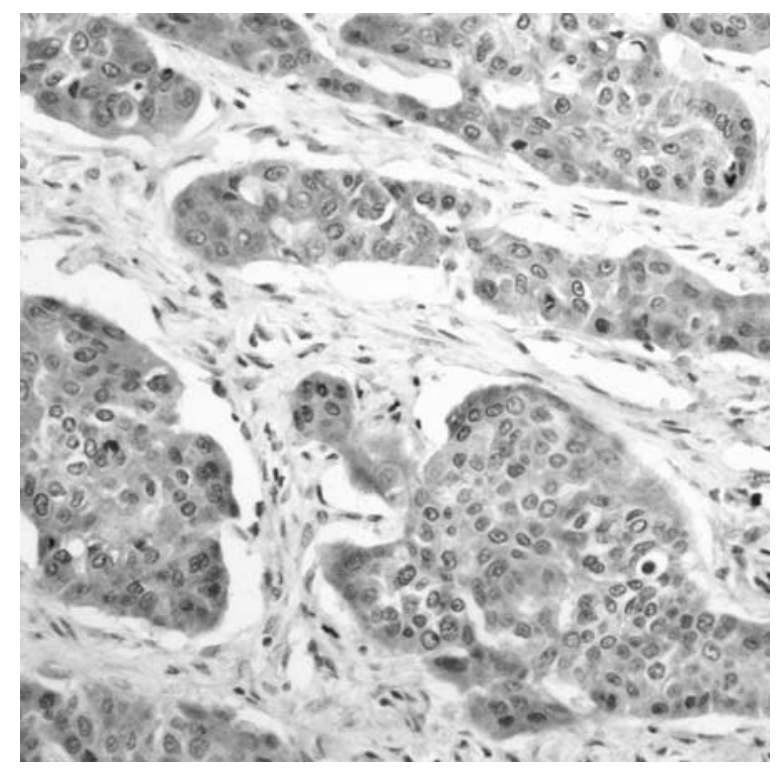

Figure 4. Representative immunohistochemical positive expression for EGFR-c. Original magnification, x200. products, each reaction was also carried out without reverse transcriptase. In addition, no template control was run for the RT and PCR stages for each of the primer sets and none showed any visible PCR products. For the qualitative and quantitative analysis of silver nitrate-stained gels a video densitometer (Biotec-Fischer, Reiskirchen, Germany) with the software program Gel-Pro ${ }^{\circledR}$ analyzer 3.0 (Media Cybernetics, USA) was used. RT-PCR reactions were repeated 3 times for each sample. The integrated optical density (IOD) of the bands in a digitized picture was measured. STAT-3 gene expression was determined as the ratio of STAT-3 to B-actin. In the PCR reactions, ratios were normalized to the appropriate control ratio. In normal non-cancerous laryngeal samples STAT-3/ß-actin ratios were $0.263 \pm 0.01$ (mean \pm SD), respectively. The cut-off value for the STAT-3 positive results (mean \pm 3 SD) was calculated as 0.293 , respectively.

Statistical analysis of data. The statistical calculations were made by the StatPlus 2007 software (AnalystSoft, Vancouver, Canada). None of the parameters recorded in the tumor material passed tests for being normally distributed (KolmogorovSmirnow test). Therefore, non-parametric statistical tests for the association between the EGFR IHC index and mRNA STAT3 expression were used to analyze the results (MannWhitney U test and Spearman's rank analysis). The nonparametric Kruskal-Wallis and one-way ANOVA tests were 
Table II. Distribution of EGFR membranous and cytoplasmic coexpression.

\begin{tabular}{lcccc}
\hline EGFR-m & $1(<25 \%)$ & $2(25 \div 50 \%)$ & $3(>50 \%)$ & Total \\
\hline EGFR-c & & & & \\
0 (None) & 11 & 6 & 11 & $28 / 45(62.2 \%)$ \\
1 (Weak or intermediate) & 6 & 2 & 3 & $11 / 45(24.5 \%)$ \\
2 (Strong) & 0 & 1 & 5 & $6 / 45(13.3 \%)$ \\
Total & $17 / 45(37.8 \%)$ & $9 / 45(20 \%)$ & $19 / 45(42.2 \%)$ & 45 \\
\hline
\end{tabular}

used to estimate the association between the EGFR index and median concentration ratio of each cytokine. Dunnett correction was applied to adjust for multiple comparisons. $\mathrm{P}<0.05$ was considered to be significant.

\section{Results}

Our experiments confirm the membranous EGFR (EGFR-m) positive expression in $93.3 \%$ of tumor samples and the cytoplasmic EGFR (EGFR-c) positive expression in $37.8 \%$ cases of squamous cell laryngeal carcinoma. An EGFR membrane staining index of $<25 \%$ manifested itself in 17 out of $45(37.8 \%$ ) samples and the index of $25 \div 50 \%$ in 9 out of 45 (20.0\%) cases and $>50 \%$ was observed in 19 out of $45(42.2 \%)$ cases. Cytoplasmic staining intensity, classified as negative, was observed in $62.2 \%(28 / 45)$ of tumor samples. The remaining $37.8 \%(17 / 45)$ of cases revealed positive (weak to moderate or strong) cytoplasmic staining. Representative IHC stainings for EGFR-m and EGFR-c are shown in Figs. 1-4. Immunohistochemical scores of EGFR-m and EGFR-c coexpression of epidermal growth factor receptor are shown in Table II. Non-cancerous normal epithelial cells used as a control and laryngeal neoplastic cells used as a studied sample isolated from the tumors of 24 patients after total larynx resection were evaluated for the expression of STAT3 mRNA by RT-PCR.

We have demonstrated that laryngeal cancerous epithelial (marginal and central tumor) and non-cancerous normal epithelial cells expressed mRNA for STAT3. Additionally, we have found that the mean expression of the signal transducer and activator of transcription-3 factor in tumor cells was $0.23 \pm 0.11 \mathrm{IOD}_{\mathrm{STAT} 3 / \text {-actin }}$. Our study has revealed that central cancer and marginal tumor cells demonstrated $0.25 \pm 0.13$ and $0.22 \pm 0.09 \mathrm{IOD}_{\mathrm{STAT} / \beta \text {-actin }}$ expression of STAT3, respectively. The level of STAT3 in the noncancerous normal epithelial cells was $0.19 \pm 0.12 \mathrm{IOD}_{\mathrm{STAT} 3 / \mathrm{B}-}$ actin, which is the lowest recorded STAT3 level in comparison with the expression in cancerous laryngeal cells. In the present experiment, the supernatants of purified PBMC cultures and whole peripheral blood samples, with and without PHA stimulation, were collected after 21, 42 and $72 \mathrm{~h}$ in the 45 cases. The secretion patterns of proinflammatory/ regulatory cytokines (TNF $\alpha$, IL-2, IL-6, IL-8 and IFN $\gamma$ ) were measured using an ELISA test. Among these five cytokines, either secreted by freshly isolated PBMC cultures or measured in whole peripheral blood samples, IL-6 and -8 have been detected in the highest concentrations. The cytokine

\section{TCC TMC NCC}

EGFR-m $\leq 50 \%$

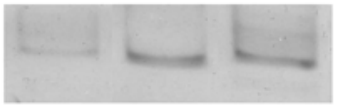

EGFR-m > 50\%

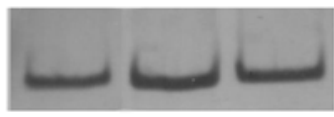

$\beta$-actin

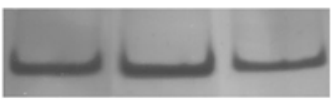

Figure 5. STAT3 mRNA expression by RT-PCR in neoplasm cells isolated from tumors with an EGFR-m index of $\leq 50 \%$ and $>50 \%$ positive cells

concentrations either produced by purified PBMC cultures or measured in whole blood are shown in Table III.

Relationship between EGFR-m status and STAT3 expression in neoplastic cells. To verify whether EGFR-m determines STAT3 expression in tissues of squamous cell laryngeal carcinoma or not, we juxtaposed the mRNA amplification level obtained by PCR for STAT3 with EGFR immunoexpression. Our study has revealed a statistically significant dependence of EGFR status on STAT3 expression in neoplastic tissues. We have found that the mean expression in tumor central and marginal cells, isolated from tumors with an EGFR-m index of $\leq 50 \%$ positive and non-cancerous normal epithelial cells were: TCC, $0.16 \pm 0.9$ IOD $_{\text {STAT3/B-actin }}$; TMC, $0.2 \pm 0.04 \mathrm{IOD}_{\mathrm{STAT} 3 / \beta \text {-actin }}$ and NCC, $0.19 \pm 0.06$ $\mathrm{IOD}_{\mathrm{STAT} / \beta \text {-actin }}$, respectively. Our study has revealed that the mean expression of STAT3 in tumor central and marginal cells, isolated from neoplasms with an EGFR-m index of $>50 \%$ positive and in non-cancerous normal epithelial cells were: TCC, $0.32 \pm 0.15 \mathrm{IOD}_{\mathrm{STAT} 3 / \mathrm{B}-\text { actin }}$; TMC, $0.31 \pm 0.09$ $\mathrm{IOD}_{\mathrm{STAT} 3 / \beta \text {-actin }}$ and NCC, $0.3 \pm 0.05 \mathrm{IOD}_{\mathrm{STAT} / / 3 \text {-actin }}$, respectively. Moreover, we have observed that tumors, in which $>50 \%$ of cells were sensitive to IHC EGFR-m staining were characterized by the most frequent presence of STAT3 expression (Spearman's test: $\mathrm{r}=0.85, \mathrm{p}=0.01$ ). The expression of STAT3 mRNA by RT-PCR in neoplasm cells isolated from tumors with an EGFR-m index of $\leq 50 \%$ and $>50 \%$ is shown in Fig. 5.

Relationship between EGFR-c status and STAT3 expression in neoplastic cells. To verify whether EGFR-c determines 
Table III. Mean concentrations of cytokines secreted by purified PBMC cultures or measured in whole blood.

\begin{tabular}{|c|c|c|c|c|c|}
\hline & $\begin{array}{c}\mathrm{TNF} \alpha \\
{[\mathrm{ng} / \mathrm{ml}]}\end{array}$ & $\begin{array}{c}\text { IL-2 } \\
{[\mathrm{ng} / \mathrm{ml}]}\end{array}$ & $\begin{array}{c}\text { IL-6 } \\
{[\mathrm{ng} / \mathrm{ml}]}\end{array}$ & $\begin{array}{c}\text { IL-8 } \\
{[\mathrm{ng} / \mathrm{ml}]}\end{array}$ & $\begin{array}{c}\text { INF } \gamma \\
{[\mathrm{ng} / \mathrm{ml}]}\end{array}$ \\
\hline \multicolumn{6}{|c|}{ Without PHA stimulation } \\
\hline \multicolumn{6}{|c|}{ Purified PBMCs } \\
\hline $21 \mathrm{~h}$ & $0.37 \pm 0.07$ & 0 & $66.01 \pm 11.49$ & $126.54 \pm 28.06$ & $0.004 \pm 0.002$ \\
\hline $42 \mathrm{~h}$ & $0.37 \pm 0.06$ & $0.0001 \pm 0.0001$ & $104.25 \pm 18.93$ & $267.98 \pm 43.33$ & $0.012 \pm 0.009$ \\
\hline $72 \mathrm{~h}$ & $0.27 \pm 0.06$ & $0.0014 \pm 0.0015$ & $143.72 \pm 24.73$ & $246.66 \pm 38.64$ & $0.033 \pm 0.018$ \\
\hline \multicolumn{6}{|c|}{ Whole blood } \\
\hline $21 \mathrm{~h}$ & $0.33 \pm 0.04$ & $0.0002 \pm 0.0001$ & $63.46 \pm 7.67$ & $109.00 \pm 12.70$ & $0.003 \pm 0.001$ \\
\hline $42 \mathrm{~h}$ & $0.21 \pm 0.03$ & $0.0006 \pm 0.0004$ & $88.64 \pm 12.58$ & $345.32 \pm 48.94$ & $0.016 \pm 0.009$ \\
\hline $72 \mathrm{~h}$ & $0.12 \pm 0.03$ & $0.0016 \pm 0.0001$ & $141.14 \pm 34.89$ & $291.13 \pm 47.68$ & $0.026 \pm 0.022$ \\
\hline
\end{tabular}

With PHA stimulation

\begin{tabular}{|c|c|c|c|c|c|}
\hline \multicolumn{6}{|c|}{ Purified PBMCs } \\
\hline $21 \mathrm{~h}$ & $0.88 \pm 0.12$ & $0.41 \pm 0.11$ & $96.97 \pm 13.32$ & $234.74 \pm 33.15$ & $1.32 \pm 0.41$ \\
\hline $42 \mathrm{~h}$ & $0.64 \pm 0.01$ & $0.38 \pm 0.11$ & $150.74 \pm 23.41$ & $711.58 \pm 298.60$ & $2.50 \pm 0.52$ \\
\hline $72 \mathrm{~h}$ & $0.38 \pm 0.07$ & $0.17 \pm 0.04$ & $191.57 \pm 28.68$ & $601.27 \pm 63.73$ & $2.25 \pm 0.33$ \\
\hline \multicolumn{6}{|c|}{ Whole blood } \\
\hline $21 \mathrm{~h}$ & $0.53 \pm 0.14$ & $0.67 \pm 0.02$ & $94.43 \pm 17.22$ & $157.57 \pm 25.76$ & $0.49 \pm 0.11$ \\
\hline $42 \mathrm{~h}$ & $0.31 \pm 0.05$ & $0.13 \pm 0.03$ & $128.28 \pm 22.30$ & $423.96 \pm 61.33$ & $1.28 \pm 0.32$ \\
\hline $\mathrm{s} 72 \mathrm{~h}$ & $0.17 \pm 0.05$ & $0.15 \pm 0.03$ & $164.25 \pm 36.23$ & $379.21 \pm 81.98$ & $1.59 \pm 0.54$ \\
\hline
\end{tabular}

STAT3 expression in tissues of squamous cell laryngeal carcinoma or not, we juxtaposed the mRNA level for STAT3 with EGFR immunoexpression. Our study has revealed that the mean expression of STAT3 in tumor central and marginal cells, isolated from neoplasms with a negative EGFR-c index and in non-cancerous normal epithelial cells were TCC, $0.2 \pm 0.15 \mathrm{IOD}_{\mathrm{STAT} 3 / \text {-actin }} ; \mathrm{TMC}, 0.17 \pm 0.07 \mathrm{IOD}_{\mathrm{STAT} 3 / \text {-actin }}$ and NCC, $0.16 \pm 0.12 \mathrm{IOD}_{\mathrm{STAT} 3 / \beta \text {-actin }}$, respectively. The mean expression of STAT3 in tumor central and marginal cells, isolated from neoplasms with a positive EGFR-c index was TCC, $0.32 \pm 0.08 \mathrm{IOD}_{\mathrm{STAT} / / \beta \text {-actin }}$; TMC, $0.31 \pm 0.14 \mathrm{IOD}_{\mathrm{STAT} / / \beta \text {-actin }}$ and NCC, $0.3 \pm 0.12 \mathrm{IOD}_{\mathrm{STAT} 3 / \mathrm{B} \text {-actin }}$. Thus, we found the relationship between EGFR-c status and STAT3 expression in laryngeal carcinoma. In our experiment, neoplasm tissues with positive EGFR staining in cell cytoplasm have demonstrated a higher level of STAT3 expression (Spearman's test: $\mathrm{r}=0.74, \mathrm{p}=0.02$ ). Interestingly, no relationships of statistical significance were found between EGFR and STAT3 expression after isolated tumor cells had been divided into two subgroups (central and marginal). The expression of STAT3 mRNA by RT-PCR in neoplasm cells isolated from tumors with EGFR-c positive and negative expression is shown in Fig. 6.

Relationship between EGFR-m status and proinflammatory/ regulatory cytokine pattern. To confirm whether proinflammatory/regulatory cytokines, expressed by purified PBMCs and measured in whole blood, determine EGFR expression,

\section{TCC TMC NCC}

EGFR-c negative
EGFR-c positive
$\beta$-actin

Figure 6. STAT3 mRNA expression by RT-PCR in neoplasm cells isolated from tumors with an EGFR-c positive and negative expression.

we examined the concentrations of selected cytokines and juxtaposed them with immunohistochemical results. Our data demonstrate significant differences between EGFR-m expression and $\mathrm{TNF} \alpha$ concentration as recorded in isolated PBMC supernatants in a 72-h culture with and without PHA stimulation (Kruskal-Wallis and one-way ANOVA tests: $\mathrm{p}=0.03$ and $\mathrm{p}=0.04)$. The highest mean $\mathrm{TNF} \alpha$ concentrations in the supernatants of purified PBMCs were $0.94 \pm 0.15$ and $0.68 \pm 0.02 \mathrm{ng} / \mathrm{ml}$ in 21 - and 42 -h cultures, with PHA stimulation for tumors with EGFR-m $>50 \%$ and $0.54 \pm 0.02 \mathrm{ng} / \mathrm{ml}$ in a 72-h culture, with PHA stimulation for tumors with an EGFR-m index of $25 \div 50 \%$. In addition, the highest mean $\mathrm{TNF} \alpha$ concentrations in these samples were $0.61 \pm 0.13$, $0.55 \pm 0.01$ and $0.41 \pm 0.03 \mathrm{ng} / \mathrm{ml}$ in $21-, 42$ - and 72 - $\mathrm{h}$ cultures, 


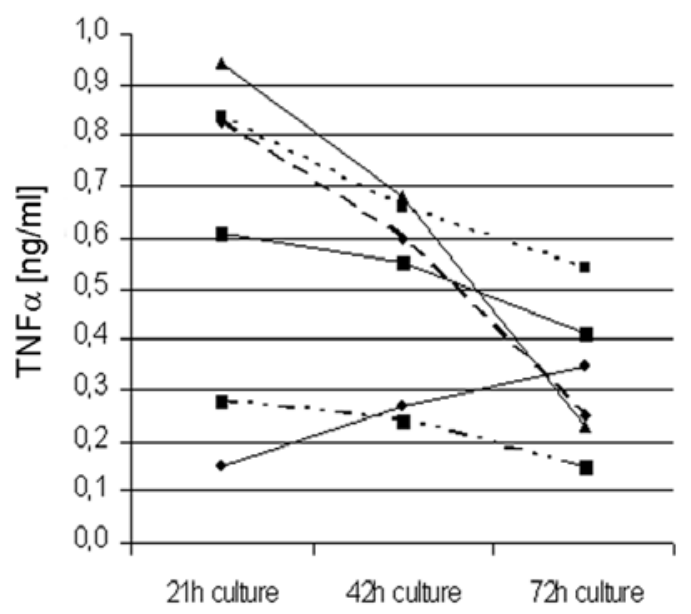

Isolated PBMCs cultures [h]

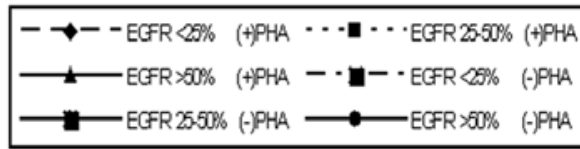

Figure 7. Mean TNF $\alpha$ concentrations secreted by purified PBMC cultures, for tumors scored using a three-tier system of EGFR-m immunoexpression.

without PHA stimulation, for tumors with an EGFR-m index of $25 \div 50 \%$, respectively. The mean $\mathrm{TNF} \alpha$ concentrations secreted by purified PBMC cultures, for tumors with EGFR-m immunoexpression are shown in Fig. 7.

In addition, we discovered significant differences between membranous EGFR immunoexpression and IL-8 concentrations in whole peripheral blood in $21-$ and $42-\mathrm{h}$ observations, with (ANOVA test: $p=0.007$ and $p=0.02$ ) and without (ANOVA test: $\mathrm{p}=0.01$ and $\mathrm{p}=0.008$ ) PHA stimulation. Dunnett correction disclosed significant differences between tumors with an EGFR-m index of $25 \div 50 \%$ and $>50 \%$ in IL-8 concentrations produced by mononuclear cells in whole blood ( $p=0.02$ and $p=0.04$ for a 21-h culture with and without PHA stimulation, respectively, and $\mathrm{p}=0.03$ for a 42 -h culture with PHA). The highest mean IL- 8 concentrations in whole peripheral blood samples were 216.2 $\pm 49.7,550.3 \pm 110.5$ and $510.4 \pm 236.3 \mathrm{ng} / \mathrm{ml}$ in $21-, 42-$ and $72-\mathrm{h}$ cultures, with PHA stimulation for tumors with EGFR-m of $>50 \%$, respectively. Moreover, the highest mean IL-8 concentrations in introduced cultures were $127.1 \pm 22.4$ and $424.5 \pm 77.5 \mathrm{ng} / \mathrm{ml}$ in 21- and 42-h cultures, without PHA stimulation, for an EGFR-m index of $>50 \%$ as well as $312.4 \pm 93.3 \mathrm{ng} / \mathrm{ml}$ in a $72-\mathrm{h}$ culture, without PHA stimulation, for tumors with an EGFR-m index of $25 \div 50 \%$. Mean IL-8 concentrations measured in whole blood, for tumors with EGFR-m immunoexpression are shown in Fig. 8.

Our results showed a significant difference between EGFR-m expression and IFN $\gamma$ level in whole blood in a 42-h culture with PHA (ANOVA test: $\mathrm{p}=0.02$ ). The highest mean IFN $\gamma$ concentration was $0.68 \pm 0.19 \mathrm{ng} / \mathrm{ml}$ in whole blood in a 21-h culture with PHA stimulation for an EGFR-m index of $25 \div 50 \%$. Moreover, the highest mean IFN $\gamma$ concentrations in

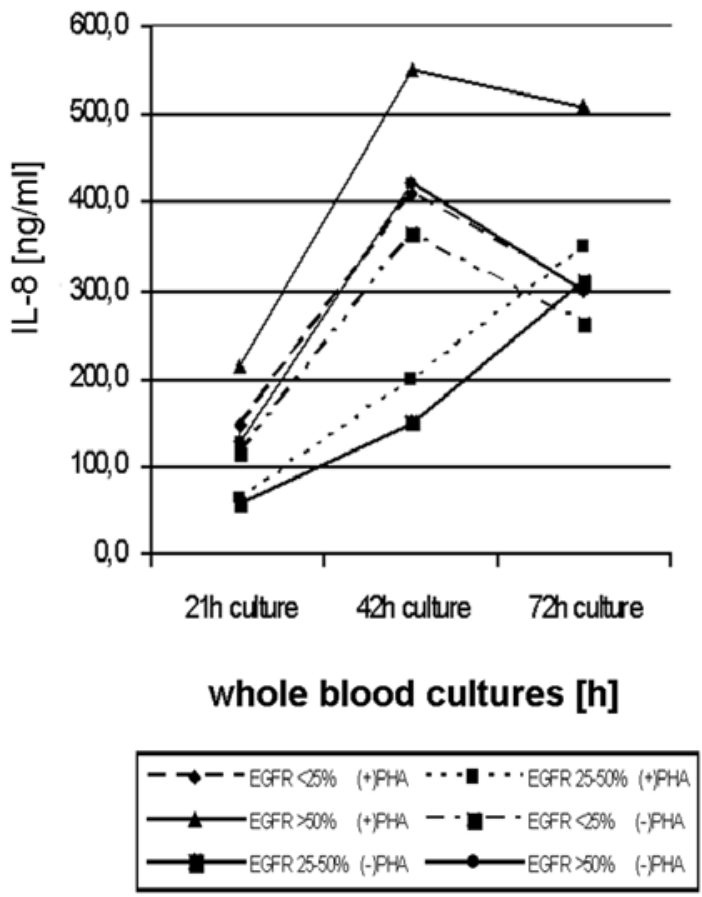

Figure 8. Mean IL-8 concentrations measured in whole blood, for tumors scored using a three-tier system of EGFR-m immunoexpression.

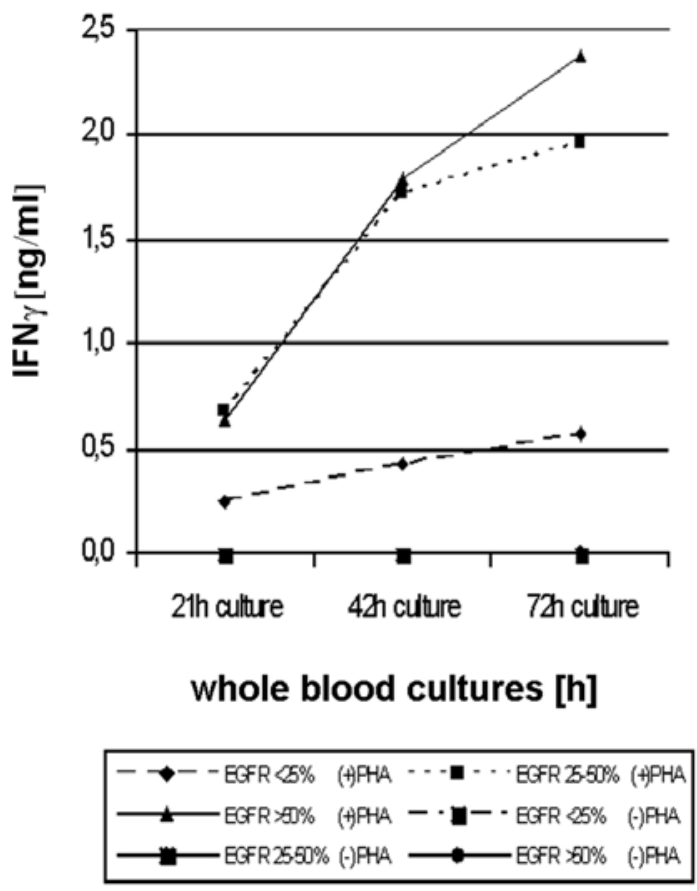

Figure 9. Mean INF $\gamma$ concentrations measured in whole blood, for tumors scored using a three-tier system of EGFR-m immunoexpression.

whole blood samples were $1.79 \pm 0.66$ and $2.38 \pm 1.76 \mathrm{ng} / \mathrm{ml}$ in 42- and 72-h cultures, with PHA stimulation, for an EGFR-m index of $>50 \%$. Mean IFN $\gamma$ concentrations measured in whole blood, for tumors with EGFR-m expression are shown in Fig. 9. However, no statistical difference between the EGFR-m index and IL-2, IL-6 concentration has been recorded. 
Relationship between EGFR-c status and proinflammatory/ regulatory cytokine pattern. To verify whether proinflammatory and regulatory cytokines determine EGFR expression in the cytoplasm of laryngeal carcinoma cells, we juxtaposed the results of our analyses. We observed significant differences between EGFR-c expression and IL-2, IL-8 or IFN $\gamma$ concentrations recorded in isolated PBMC supernatants in a 21-h culture stimulated with PHA (ANOVA test: $\mathrm{p}=0.005$, $\mathrm{p}=0.04$ and $\mathrm{p}=0.03$ for IL-2, IL- 8 and IFN $\gamma$, respectively). The highest mean concentrations of the selected cytokines were detected in tumors lacking EGFR staining. The mean concentrations of analyzed cytokines were $0.5 \pm 0.05 \mathrm{pg} / \mathrm{ml}$ for IL-2, $247.3 \pm 19.54 \mathrm{pg} / \mathrm{ml}$ for IL-8 and $1.57 \pm 0.19 \mathrm{pg} / \mathrm{ml}$ for IFN $\gamma$. In addition, after Dunnett correction, further significant differences were disclosed in IL-2 levels produced by mononuclear cells in 21-h cultures stimulated with PHA for tumors with EGFR-c expression, and scored with the use of a three-tier system, $(p=0.04$ and $p=0.04$ for EGFR classified as 0 vs. 1 and 0 vs. 2, respectively). A significant relationship between EGFR-c immunoexpression and IFN $\gamma$ concentration in whole peripheral blood for a 21-h culture with PHA stimulation (ANOVA test: $\mathrm{p}=0.02$ ) has also been revealed in our study, with the mean concentration of IFN $\gamma$ being $0.63 \pm 0.16 \mathrm{pg} / \mathrm{ml}$. Dunnett correction disclosed significant differences in secreted IFN $\gamma$ levels for tumors with EGFR cytoplasmic stages classified as 0 or $1(\mathrm{p}=0.04)$. No statistical relationship between EGFR-c staining and TNF $\alpha$ or IL-6 concentration has been found.

\section{Discussion}

EGFR is a member of the ErbB family receptors, involved in cellular proliferation in many various types of carcinomas and may be an important therapeutic target $(8-10,29-31,35)$. EGFR is a key transmembrane glycoprotein triggering a network of downstream signaling pathways, including not only cell proliferation, cell-cell adhesion and migration, but also the invasion of the tumor front, apoptosis and DNAdamage repair in neoplasm cells (8-10). Over-expression of EGFR and its ligands, such as EGF, TGF $\alpha$, amphiregulin and the presence of tyrosine kinase domain mutations have been noted in many human cancer types, such as HNSCC (1115).

Membranous and cytoplasmic EGFR immunoexpression was presented in this study. We observed that $93.3 \%$ of tumor samples possessed membranous EGFR expression. Our study shows that $37.8 \%$ of samples of the carcinoma expressed EGFR cytoplasmic staining. Based on a review of the literature overexpression of the EGFR protein is found in $34-93 \%$ of various types of human carcinomas $(4,5,44,45)$. A dispersion of results report EGFR expression or its ligands which stems from different antibodies and methods that have been used. For instance, Cohen et al (45) evaluated IHC staining for the patterns of EGFR overexpression, including membranous, cytoplasmic and total expression score. These authors demonstrated that the prognostic value of EGFR expression differs significantly when various methods are used to evaluate EGFR overexpression and that the immunohistochemical analysis is qualitative rather than quantitative. Thus, the results obtained are not consistent (44).
Investigators have confirmed the relationship between EGFR status and STAT3, and between the EGFR status and cytokine expression, such as IL-6, IL-8 or TNF $\alpha(19,20,29$ $33,40-42)$. Our results show the relationship between EGFR$\mathrm{m}$ and EGFR-c immunoexpression, and the mRNA amplification level, obtained by PCR for STAT3 as well as the concentrations of proinflammatory/regulatory cytokines secreted by PBMCs, especially IL-8, IFN $\gamma$ and TNF $\alpha$. Kuwahara et al (3) claim that IL-8 gene transcription and protein release are regulated through $\mathrm{p} 38 / \mathrm{NF}-\kappa \mathrm{B}$ activation via EGFR transactivation in a lung epithelial cell line. Nakanaga et al (41) demonstrated that EGF receptor and MAP kinase ERK1/2 are involved in IL- 8 expression by these stimuli and that TGF $\alpha$ mediates IL- 8 production. Gao et al (19) reported that cell lines expressing persistently activated mutant EGFR also produce high IL-6 levels. Similarly, Wehbe et al (40) pointed out that IL-6 overexpression resulted in an altered expression and promoter methylation of several genes, including EGFR. These mechanisms contribute to carcinogenesis and enhance tumor growth. Moreover, they indicated that an increased IL-6 expression is connected with the sensitivity of tumor cells to therapeutic treatment using methylation inhibitors (40).

In contrast, our study has failed to demonstrate an association of EGFR with the IL-6 level. Discrepancies in conclusions may be due to a high IFN $\gamma$ concentration assessed in our experiment. Croker et al (46) suggested that the SOCS (suppressor of cytokine signaling) family is involved in the negative regulation of IL-6 in vivo. They indicated an enhanced STAT phosphorylation in response to IFN $\gamma$. However, an alternative mechanism of EGFR activation with an indirect impact on the STAT3 activity pathway has also been described (21). Yang et al (29) demonstrated that IFN $\gamma$ promotes an antiproliferative effect of HER1/EGFR inhibitors on colon cancer cell lines. It has been shown that TNF $\alpha$ can reduce EGFR tyrosine phosphorylation, which results in the blockade of EGFR-mediated signal transduction. The signal transduction, in turn, can switch $\mathrm{TNF} \alpha$-induced apoptosis by stimulating caspases or by inducing ligand (TRAIL) action as an anticancer agent (30-32). Many investigators have demonstrated that the presence of $\mathrm{TNF} \alpha$, a proinflammatory cytokine, is characteristic of antitumor effects and manifests itself as an increasing vascular permeability of tumor microvasculature, which leads to an improved infiltration of monoclonal antibodies in the tumor (32). Hambek et al (31) found synergistic effects of the interaction between TNF $\alpha$ and EGFR after blocking it with monoclonal antibodies, which resulted in tumor size reduction in squamous cell carcinoma xenografts of the head and neck, uterine cervix cancer and adenocarcinomas with a high level of EGFR expression. They also noted that the combination treatment caused the increase in tumor cell apoptosis for carcinomas with a low EGFR expression (31). In several other studies, investigators demonstrated that the EGFR pathway is inhibited by blocking the activity of $\mathrm{TNF} \alpha$-converting enzyme, which induces metastatic properties, including the adhesion to fibronectin, mRNA expression of $\alpha$-integrin and the production of matrix metalloproteinase- $9(38,39)$. Notably, Ando et al (35) indicated that therapy with $\mathrm{TNF} \alpha$ induces autophosphorylation of EGFR in cross-talk signaling in lung 
cancer cases with acquired resistance to the EGFR tyrosine kinase inhibitor. Many investigators have suggested that a constitutive STAT3 activation, in response to cytokine signals, such as proinflammatory interleukins (IL-6 and TNF $\alpha$ ) or chemokines (IL-8), results in apoptosis inhibition under many human primary malignant conditions, including head and neck squamous carcinomas (HNSCC) (47-49). It is well known that proinflammatory cytokines influence the inflammatory response to tumor antigens and are implicated in the regulation of STAT3 signaling $(47,50)$. An important alternative mechanism of STAT3 activation with an impact on the epidermal growth factor receptor (EGFR) pathway has been noted in recent studies $(19,24)$. Tumor cells expressing persistently activated mutant EGFRs activate the gp130/ JAK/STAT3 pathway by IL-6 up-regulation $(19,51)$. Interestingly, in STAT3 activation the IL-6R cascade is more often reported on than the EGFR pathway $(50,52)$. Of note is that Garcia (2) showed that signaling through EGFR leads to the activation of multiple effectors, including hypoxiainducible factors (HIFs), which stimulate transcriptional activators, cytokines, growth factors and their receptors.

In conclusion, this investigation confirms a key role of EGFR in determining the proliferative and aggressive potential of the tumors studied. It also demonstrates that proinflammatory and regulatory cytokines can be committed to the activation of downstream molecules participating in neoplasm growth.

\section{Acknowledgements}

This work was supported by grants from the National Science Council (KBN 3 P05C 01725, N403 04332/2326) and research grant from the Medical University of Lodz, Poland (UM 502-12-471).

\section{References}

1. Squarize CH, Castilho RM, Sriuranpong V, Pinto DS Jr and Gutkind JS: Molecular cross-talk between the NFkappaB and STAT3 signaling pathways in head and neck squamous cell carcinoma. Neoplasia 8: 733-746, 2006.

2. Garcia JA: HIFing the brakes: therapeutic opportunities for treatment of human malignancies. Sci STKE 337: 25, 2006.

3. Kuwahara I, Lillehoj EP, Lu W, Singh IS, Isohama Y, Miyata T and Kim KC: Neutrophil elastase induces IL-8 gene transcription and protein release through $\mathrm{p} 38 / \mathrm{NF}-\{$ kappa $\} \mathrm{B}$ activation via EGFR transactivation in a lung epithelial cell line. Am J Physiol Lung Cell Mol Physiol 291: L407-L416, 2006.

4. Suzuki S, Igarashi S, Hanawa M, Matsubara H, Ooi A and Dobashi Y: Diversity of epidermal growth factor receptormediated activation of downstream molecules in human lung carcinomas. Mod Pathol 19: 986-998, 2006.

5. Bentzen SM, Atasoy BM, Daley FM, et al: Epidermal growth factor receptor expression in pretreatment biopsies from head and neck squamous cell carcinoma as a predictive factor for a benefit from accelerated radiation therapy in a randomized controlled trial. J Clin Oncol 23: 5560-5567, 2005.

6. Kijima T, Niwa H, Steinman RA, et al: STAT3 activation abrogates growth factor dependence and contributes to head and neck squamous cell carcinoma tumor growth in vivo. Cell Growth Differ 13: 355-362, 2002.

7. Bowman T, Garcia R, Turkson J and Jove R: STATs in oncogenesis. Oncogene 19: 2474-2488, 2000.

8. Dicker AP and Rodeck U: Predicting the future from trials of the past: epidermal growth factor receptor expression and outcome of fractionated radiation therapy trials. J Clin Oncol 23: 5437-5439, 2005.

9. Yarden Y and Sliwkowski MX: Untangling the ErbB signalling network. Nat Rev Mol Cell Biol 2: 127-137, 2001.
10. Salomon DS, Brandt R, Ciardiello, Ciardiello F and Normanno N: Epidermal growth factor-related peptides and their receptors in human malignancies. Crit Rev Oncol Hematol 19: 183-232, 1995.

11. Merchant NB, Voskresensky I, Rogers CM, et al: TACE/ ADAM-17: a component of the epidermal growth factor receptor axis and a promising therapeutic target in colorectal cancer. Clin Cancer Res 14: 1182-1191, 2008

12. Révillion F, Lhotellier V, Hornez L, Bonneterre J and Peyrat JP: ErbB/HER ligands in human breast cancer, and relationships with their receptors, the bio-pathological features and prognosis. Ann Oncol 19: 73-80, 2008.

13. Lee JW, Soung YH, Kim SY, et al: Somatic mutations of EGFR gene in squamous cell carcinoma of the head and neck. Clin Cancer Res 11: 2879-2882, 2005.

14. Dowell JE and Minna JD: Chasing mutations in the epidermal growth factor in lung cancer. N Engl J Med 352: 830-832, 2005.

15. Sellers WR and Meyerson M: EGFR gene mutations: a call for global x global views of cancer. J Natl Cancer Inst 97: 326-328, 2005.

16. Haura EB, Turkson J and Jove R: Mechanisms of disease: Insights into the emerging role of signal transducers and activators of transcription in cancer. Nat Clin Pract Oncol 2: 315-324, 2005.

17. Leong PL, Andrews GA, Johnson DE, et al: Targeted inhibition of Stat 3 with a decoy oligonucleotide abrogates head and neck cancer cell growth. Proc Natl Acad Sci USA 100: 4138-4143, 2003.

18. Masuda M, Suzui M, Yasumatu R, et al: Constitutive activation of signal transducers and activators of transcription 3 correlates with cyclin D1 overexpression and may provide a novel prognostic marker in head and neck squamous cell carcinoma. Cancer Res 62: 3351-3355, 2002.

19. Gao SP, Mark KG, Lesli K, et al: Mutations in the EGFR kinase domain mediate STAT3 activation via IL-6 production in human lung adenocarcinomas. J Clin Invest 117: 3846-3856, 2007.

20. Lee TL, Yeh J, Van Waes C and Chen Z: Epigenetic modification of SOCS-1 differentially regulates STAT3 activation in response to interleukin-6 receptor and epidermal growth factor receptor signaling through JAK and/or MEK in head and neck squamous cell carcinomas. Mol Cancer Ther 5: 8-19, 2006.

21. Sriuranpong V, Par JI, Amornphimoltham P, Patel V, Nelki BD and Gutkind JS: Epidermal growth factor receptor-independent constitutive activation of STAT3 in head and neck squamous cell carcinoma is mediated by the autocrine/paracrine stimulation of the interleukin 6/gp130 cytokine system. Cancer Res 63: 2948-2956, 2003.

22. Hirano T, Ishihar K and Hibi M: Roles of STAT3 in mediating the cell growth, differentiation and survival signals relayed through the IL-6 family of cytokine receptors. Oncogene 19: 2548-2556, 2000.

23. Schafer ZT and Brugge JS: IL-6 involvement in epithelial cancers. J Clin Invest 117: 3660-3663, 2007.

24. Haura EB, Zhen Z, Son L, Cantor A and Bepler G: Activated epidermal growth factor receptor-Stat-3 signaling promotes tumor survival in vivo in non-small cell lung cancer. Clin Cancer Res 11: 8288-8294, 2005.

25. Yu H and Jove R: The STATs of cancer - new molecular targets come of age. Nat Rev Cancer 4: 97-105, 2004.

26. Seki Y, Suzuk N, Imaizumi M, Iwamoto T, Usami N, Ueda Y and Hamaguchi M: STAT3 and MAPK in human lung cancer tissues and suppression of oncogenic growth by JAB and dominant negative STAT3. Int J Oncol 24: 931-934, 2004.

27. Grandis JR, Drenning SD, Zeng Q, et al: Constitutive activation of Stat3 signaling abrogates apoptosis in squamous cell carcinogenesis in vivo. Proc Natl Acad Sci USA 97: 4227-4232, 2000.

28. Grandis JR, Drenning SD, Chakraborty A, Zhou MY, Zeng Q, Pitt AS and Tweardy DJ: Requirement of Stat3 but not Stat1 activation for epidermal growth factor receptor- mediated cell growth in vitro. J Clin Invest 102: 1385-1392, 1998.

29. Yang JL, Qu XJ, Hayes VM, Brenner PC, Russell PJ and Goldstein D: Erlotinib (OSI-774)-induced inhibition of transitional cell carcinoma of bladder cell line growth is enhanced by interferon-alpha. BJU Int 6: 1539-1545, 2007.

30. Teraishi F, Kagawa S, Watanabe T, et al: ZD1839 (Gefitinib, 'Iressa'), an epidermal growth factor receptor-tyrosine kinase inhibitor, enhances the anti-cancer effects of TRAIL in human esophageal squamous cell carcinoma. FEBS Lett 579: 4069-4075, 2005. 
31. Hambek M, Solbach C, Schnuerch HG, et al: Tumor necrosis factor alpha sensitizes low epidermal growth factor receptor (EGFR)-expressing carcinomas for anti-EGFR therapy. Cancer Res 61: 1045-1049, 2001.

32. Perez M, Haschke B and Donato NJ: Differential expression and translocation of protein tyrosine phosphatase 1B-related proteins in ME-180 tumor cells expressing apoptotic sensitivity and resistance to tumor necrosis factor: potential interaction with epidermal growth factor receptor. Oncogene18: 967-978, 1999.

33. Hoffmann M, Schmidt M and Wels W: Activation of EGF receptor family members suppresses the cytotoxic effects of tumor necrosis factor-alpha. Cancer Immunol Immunother 47: $167-175,1998$

34. Ueno Y, Sakurai H, Matsuo M, Choo MK, Koizumi K and Saiki I Selective inhibition of TNF-alpha-induced activation of mitogen-activated protein kinases and metastatic activities by gefitinib. Br J Cancer 92: 1690-1695, 2005.

35. Ando K, Ohmori T, Inoue F, et al: Enhancement of sensitivity to tumor necrosis factor alpha in non-small cell lung cancer cells with acquired resistance to gefitinib. Clin Cancer Res 11: 8872-8879, 2005.

36. Perez M and Donato NJ: Activation of epidermal growth factor receptor tyrosine phosphorylation by tumor necrosis factor correlates with loss of cytotoxic activity. J Interferon Cytokine Res 16: 307-314, 1996.

37. Kenny PA and Bissell MJ: Targeting TACE-dependent EGFR ligand shedding in breast cancer. J Clin Invest 117: 337-345, 2007.

38. Kenny PA: Three-dimensional extracellular matrix culture models of EGFR signalling and drug response. Biochem Soc Trans 35: 665-668, 2007.

39. Zhang Q, Thomas SM, Lui VW, et al: Phosphorylation of TNFalpha converting enzyme by gastrin-releasing peptide induces amphiregulin release and EGF receptor activation. Proc Natl Acad Sci USA 103: 6901-6906, 2006.

40. Wehbe H, Henson R, Meng F, Mize-Berg J and Patel T: Interleukin-6 contributes to growth in cholangiocarcinoma cells by aberrant promoter methylation and gene expression. Cancer Res 66: 10517-10524, 2006.
41. Nakanaga T, Nadel JA, Ueki IF, Koff JL and Shao MX: Regulation of interleukin-8 via an airway epithelial signaling cascade. Am J Physiol Lung Cell Mol Physiol 292: L1289-L1296, 2007.

42. Bancroft CC, Chen Z, Yeh J, et al: Effects of pharmacologic antagonists of epidermal growth factor receptor, PI3K and MEK signal kinases on NF-kappaB and AP-1 activation and IL-8 and VEGF expression in human head and neck squamous cell carcinoma lines. Int J Cancer 99: 538-548, 2002.

43. Sobin LH and Wittekind C (eds): TNM Classification of Malignant Tumours, 6th edition. Wiley J \& Sons, Hoboken, NJ, 2002 .

44. Fogarty GB, Conus NM, Chu J and McArthur G: Characterization of the expression and activation of the epidermal growth factor receptor in squamous cell carcinoma of the skin. Br J Dermatol 156: 92-98, 2007.

45. Cohen D, Lane B, Jin T, et al: The prognostic significance of epidermal growth factor receptor expression in clear-cell rena cell carcinoma: a call for standardized methods for immunohistochemical evaluation. Clin Genitourin Cancer 5: 264-270, 2007.

46. Croker BA, Krebs DL, Zhang JG, et al: SOCS3 negatively regulates IL-6 signaling in vivo. Nat Immunol 4: 507-509, 2003.

47. Berishaj M, Gao SP, Ahmed S, et al: Stat3 is tyrosine-phosphorylated through the interleukin-6/glycoprotein 130/Janus kinase pathway in breast cancer. Breast Cancer Res 9: R32, 2007.

48. Kotha A, Sekharam M, Cilenti L, et al: Resveratrol inhibits Src and Stat 3 signaling and induces the apoptosis of malignant cells containing activated Stat3 protein. Mol Cancer Ther 5: 621-629, 2006.

49. Leslie K, Lang C, Devgan G, et al: Cyclin D1 is transcriptionally regulated by and required for transformation by activated signal transducer and activator of transcription 3. Cancer Res 66: 2544-2552, 2006

50. Kishimoto T: Interleukin-6: discovery of a pleiotropic cytokine. Arthritis Res Ther 8: S2, 2006.

51. Yang J, Liao X, Agarwal MK, Barnes L, Auron PE and Stark GR: Unphosphorylated STAT3 accumulates in response to IL-6 and activates transcription by binding to NFkappaB. Genes Dev 21: 1396-1408, 2007

52. Knüpfer H and Preiss R: Significance of interleukin-6 (IL-6) in breast cancer. Breast Cancer Res Treat 102: 129-135, 2007. 